\title{
Organochlorine Compounds in Beached Plastics and Marine Organisms
}

\author{
Luís M. Nunes ${ }^{1,2 *}$ \\ ${ }^{1}$ Faculdade de Ciências e Tecnologia, Universidade do Algarve, Faro, Portugal, ${ }^{2}$ Civil Engineering Research and Innovation for \\ Sustainability (CERIS), Instituto Superior Técnico, Lisboa, Portugal
}

Here we compare bioaccumulation factors in marine organisms to partition ratios in marine debris for dichlorodiphenyltrichloroethane and polychlorinated biphenyls. Both organochlorines are synthetic persistent organic pollutants emitted into the environment since the beginning of the last century in approximately equal amounts. Their vast use and dispersion have resulted in approximately similar median concentrations of the two organochlorines in some pelagic organisms, namely in the liver and muscle tissue of fish. Molluscs, on the other hand, show higher median uptake of PCBs (median = $2.34 \mathrm{ng} / \mathrm{g}$ ) than of DDTs (median $=1.70 \mathrm{ng} / \mathrm{g}$ ), probably reflecting more localized conditions. We found that the bioaccumulation factors can be several orders of

\section{OPEN ACCESS}

Edited by: Nsikak U. Benson,

Covenant University, Nigeria

Reviewed by:

Edu Inam,

Centre for Energy and Environmental Sustainability Research in the University of Uyo, Nigeria Mandana Barghi,

Korea University, South Korea

*Correspondence: Luís M. Nunes Inunes@ualg.pt

Specialty section: This article was submitted to Toxicology, Pollution and the Environment,

a section of the journal

Frontiers in Environmental Science

Received: 27 September 2021

Accepted: 08 December 2021

Published: 10 January 2022

Citation:

Nunes LM (2022) Organochlorine Compounds in Beached Plastics and Marine Organisms.

Front. Environ. Sci. 9:784317. doi: 10.3389/fenvs.2021.784317 magnitude higher than the partition ratios. For instance, the median concentrations of organochlorines in the different matrices of fish, birds, and mammals are between one to four orders of magnitude higher than those found in marine debris, when lipid-normalized; or up to two orders of magnitude when measured as wet-weight. But, in molluscs, bioaccumulation/partition equals unity, which agrees with previous studies using passive samplers. Future research should focus on reducing sources of uncertainty by 1) homogenization of chemical procedures; 2) better assessment of chemical partition equilibrium between water and polymers in environmental conditions; 3) use of (multi) polymer passive samplers better aimed at mimicking uptake of specific living tissues.

Keywords: marine organisms, marine plastic debris, PCB, DDT, passive sampler, OSPAR commission, pellet watch

\section{INTRODUCTION}

The performance of passive samplers to predict concentrations of persistent contaminants in organisms other than bivalves was considered for some time as unclear (USEPA, 2012a; ICES, 2013). However, more recent studies have found good agreement between concentrations in passive equilibrium samplers (PES) and those in fish (Cerveny et al., 2016; Rusina et al., 2017). This opens the possibility of finding similar results for other organisms, allowing biota monitoring to be supplemented by PES and improving contaminant modelling and risk assessment at the higher trophic levels.

In the present work, we explore this biota-PES relationship using a synoptic approach using large environmental databases for the northeast Atlantic region, as opposed to the most frequent of local case-study analysis (ICES, 2013). The synoptic approach complements the latter by "averaging" local results and expanding the analysis for a larger set of marine organisms.

For the synoptic analysis, two hydrophobic organochlorine compounds (OCCs) were chosen: dichlorodiphenyltrichloroethane (DDT) and polychlorinated biphenyls (PCB), analysed in marine 
organisms and in beached plastic pellets. The latter behave like mobile PES (Ogata et al., 2009; Shi et al., 2020). The study focused on the North-East Atlantic, corresponding to the territorial seas of the 16 Contracting Parties of the OSPAR Convention (from Oslo and Paris Conventions, "OS" for Oslo and "PAR" for Paris) (www.ospar.org), expanding over a total area of 13.5 million $\mathrm{km}^{2}$.

DDT, which has been marketed since the early 1940s, remains as one of the twelve insecticides currently recommended for disease control exclusively by the World Health Organization (WHO) and allowed under the Stockholm Convention on Persistent Organic Pollutants. Global emissions of DDT in the period of 1950-1990 were estimated to be between $1.2 \times 10^{6}$ and $1.5 \times 10^{6}$ tons (UNEP, 2003; Semeena and Lammel, 2005). Since 2003, there have been three countries reporting DDT production, namely, India, China, and the Democratic People's Republic of Korea. From 2003 to 2007, average DDT production was around $5 \times 10^{3}$ tons per year, diminishing further from 2008 to 2014, to about $3.5 \times 10^{3}$ tons per year (Van Den Berg et al., 2017), after China and DPR Korea phased out their production. Between 1950 and 2020, the total global emissions may amount to $1.24 \times$ $10^{6}$ to $1.54 \times 10^{6}$ tons. Half-lives are estimated to be 180 days in water, 360 days in soil, 4.44 years in sediment, and 3.1 days in the atmosphere (USEPA, 2012b). Mansouri et al. (2017) report longer environmental half-lives, between 2 and 15 years for $p, p$ -DDT and o,p -DDT. Degradation of DDT in environmental compartments is notoriously slow and is close to zero in seawater. Some researchers assume that DDT removal from the environment is by degradation in soil only, represented as a first-order process $\left(4.05 \times 10^{-9} \mathrm{~s}^{-1}\right.$ at $298 \mathrm{~K}$, equivalent to a halflife of about 5.4 years, doubling per $10 \mathrm{~K}$ of temperature increase) (Hornsby et al., 1996). Background concentrations of DDT are suggested to be $1.0 \mathrm{ng} / \mathrm{g}$ (0.0 log units) wet weight in blue mussels, 200 (2.3 log units) $\mu \mathrm{g} / \mathrm{g}$ wet weight in cod liver, and $50 \mathrm{ng} / \mathrm{g}$ (1.7 log units) wet weight in herring muscle (EEA, 2003).

Polychlorinated biphenyls (PCBs) are a group of man-made oily liquids or solids, with no smell or taste. They are very stable mixtures that are resistant to extreme temperature and pressure, have low flammability, a high boiling point and electrical insulating properties. Thus, PCBs have many applications in electrical equipment like capacitors and transformers, and in hydraulic fluids, heat transfer fluids, lubricants, and plasticizers. Their production began in the late 1920s and continued until its ban, first by the USA in 1977, and later by the global ban under the Stockholm Convention in 2001, which entered into force in 2004. During this period it is estimated that about $2 \times 10^{6}$ tons of PCBs have been produced, of which about $2 \times 10^{5}$ tons remain in mobile environmental reservoirs (WHO, 2003). Half-lives for PCB 153, used here as a proxy for the sum of PCBs, are the same as DDT, except for the atmosphere, where a half-life of 65.4 days (USEPA, 2012b) allows for faster atmospheric mobility of PCB away from the location of release. The persistence of PCB congeners increases as the degree of chlorination and structural uniformity increase. While PCBs are very resistant to abiotic degradation, biodegradation occurs under both aerobic and anaerobic conditions, mostly in sediments and soils (WHO, 2003). Background concentrations of PCB are $2.0 \mathrm{ng} / \mathrm{g}$ (0.30 log units) wet weight in blue mussels, $100 \mu \mathrm{g} / \mathrm{g}$ (2.0 log units) wet weight in the cod liver, and $150 \mathrm{ng} / \mathrm{g}$ (2.18 log units) wet weight in herring muscle (EEA, 2003).

In general there have been decreasing trends in environmental concentrations of OCCs, although geographic differences are pronounced (UNEP, 2003). The leaking of PCB-rich fluids from equipment, industrial facilities, and incorrect disposal may be the cause for their slower environmental diminution in some places. For instance, the high atmospheric deposition rates reported in the Baltic Sea $\left(10-15 \mathrm{ng} / \mathrm{m}^{2} /\right.$ day $)$ reflect localized sources. In contrast, lower rates of PCB deposition in European and Mediterranean regions (ranging from 1.2 to $5.6 \mathrm{ng} /$ $\mathrm{m}^{2} /$ day), is probably due to the generalized mechanisms of atmospheric circulation in the area (UNEP, 2003). As for DDT, its use for vector control is still contributing to a localized increase in environmental concentrations.

In its 2019 assessment, the European Environment Agency concluded that (EEA, 2019) concentrations of DDT in recent years have generally been moderate in mussels and fish from the North-East Atlantic Ocean and Baltic Sea, and in mussels from the Mediterranean Sea. In the North-East Atlantic Ocean, localized high concentrations of DDT may pose a risk to marine organisms. A general downward trend was found for the North-East Atlantic Ocean from 2003 to 2014, but no general trends were detected from 2008 to 2017, which indicates that the impact of abatement policies, as a whole, may have stabilized. Concentrations of PCBs in recent years have been lower, except for localised high concentrations found in mussels and fish in the North-East Atlantic Ocean and Baltic Sea, and in mussels in the Mediterranean Sea. A general downward trend was found for the North-East Atlantic Ocean and the Baltic Sea from 2004 to 2014, which only continued in the Baltic.

In coastal waters, the input of chemicals from land via discharges of sewage and industrial effluents and rivers are the main sources of OCCs, whereas atmospheric deposition is the major pollutant source in open seawaters (Scrimshaw and Lester, 1996). Consequently, their concentrations in seawater show decreasing gradients offshore, in the low $\mathrm{pg} / \mathrm{L}$ range which makes reliable quantification difficult. Being very hydrophobic, these OCCs accumulate in sorbing materials including the organic fraction present in suspended matter, living tissues, and synthetic polymers. Thus, bivalve molluscs are being used as sentinel organisms to reflect water quality, bioavailability and bioaccumulation impacts on edible species (Lohmann and Muir, 2010), though it is impossible to find one single species that could be used across the entire world. The limitations of these "living samplers" led to the development of non-living passive samplers, which are considered as promising surrogates for organisms, mimicking bioaccumulation (Figueiredo et al., 2017). Many different devices exist for sampling organic contaminants in water (Vrana et al., 2005), but those using single-phase polymers have been increasingly used, including silicone, polyoxymethylene, and Polyethylene (PE) (Lohmann, 2012).

Plastic pellets are a nuisance to marine life. Their ingestion can cause physical harm, such as internal injuries and impaired ability to breathe, swallow, digest food properly, or immediate death. Following ingestion, hazardous chemicals can be transferred to fish, inducing hepatic stress (OSPAR Comission, 2018). To better 
TABLE 1 | DDT samples in different matrices in organisms and plastic pellets.

\begin{tabular}{|c|c|c|c|c|c|c|c|}
\hline & \multirow{3}{*}{ Matrix } & \multirow{3}{*}{ Code $^{a}$} & & \multicolumn{4}{|c|}{ Nb. of samples } \\
\hline & & & \multicolumn{3}{|c|}{ DDTs } & \multicolumn{2}{|c|}{ PCBs } \\
\hline & & & Basis $^{b}$ & $\mathbf{w}$ & $\mathbf{L}$ & $\mathbf{w}$ & $\mathbf{L}$ \\
\hline \multirow[t]{16}{*}{ Organisms } & Blubber & BB & & 279 & & 362 & \\
\hline & Blood cells & $\mathrm{BC}$ & & 20 & & - & \\
\hline & Blood & $\mathrm{BL}$ & & 16 & & 16 & \\
\hline & Blood serum & BS & & 20 & & - & \\
\hline & Egg(s) & $E G$ & & & 100 & - & \\
\hline & Epidermis (skin) & EP & & - & & 5 & \\
\hline & Fat & FA & & 77 & & 73 & \\
\hline & Kidney & $\mathrm{KI}$ & & - & & 5 & \\
\hline & Liver & $\mathrm{LI}$ & & 1750 & 1376 & 342 & 126 \\
\hline & Muscle & $\mathrm{MU}$ & & 916 & 3538 & 402 & 915 \\
\hline & Roe (fish eggs) & $\mathrm{RO}$ & & 4 & & - & \\
\hline & Whole soft-body & SB & & 120 & 195 & 212 & 39 \\
\hline & Miscellaneous & SI & & 2 & & 2 & \\
\hline & Tail muscle & TM & & 3 & & 5 & \\
\hline & Whole organism & WO & & 47 & & 5 & \\
\hline & Total & & & 3254 & 5209 & 1429 & 1080 \\
\hline \multirow[t]{6}{*}{ Pellets } & Atlantic Ocean & Atl & & 86 & & 134 & \\
\hline & Indic Ocean & Ind & & 29 & & 49 & \\
\hline & Mediterranean Sea & Med & & 19 & & 47 & \\
\hline & North Sea & North & & 11 & & 13 & \\
\hline & Pacific Ocean & Pac & & 112 & & 140 & \\
\hline & Total & & & 257 & & 383 & \\
\hline
\end{tabular}

aFor a complete list of matrix code see https://vocab.ices.dk/under "Matrix."

${ }^{b}$ Basis: lipid weight (i.e., fat weight); wet weight (i.e., fresh weight).

understand the exposure of marine life to chemicals sorbed in plastic debris, beached plastic resin pellets were proposed as easily collectible, low-cost passive samplers for some persistent organic pollutants within the International Pellet Watch project (Ogata et al., 2009). Project participants around the world voluntarily collect plastic resin pellets from beaches and send them to a centralized laboratory in Japan via airmail. The project constitutes the largest repository of such information currently available on a global scale.

In this article, we estimate concentrations in marine organisms and beached plastic pellets using data from publicly available databases. From these, the ratios between concentrations in organisms and those in marine pellets are computed and discussed, including the relative contribution of uncertainty sources. Finally, knowledge gaps are identified for future research.

\section{MATERIALS AND METHODS}

Data on total DDT (DDTs) and total PCB (PCBs) concentrations in marine organisms were retrieved from the International Council for the Exploration of the Sea (ICES), freely available at the institution's website (https://data.ices.dk/). The exhaustive dataset includes organisms that rely exclusively on the sea to feed and others that may eventually feed inland, such as many coastal birds and polar bears. The dataset contains information regarding date of sampling; location of the sampling point, in decimal geographic coordinates; concentration of the chemical (ng/g); identification of the analysed species (Genera species); matrix where the sample was taken (see Table 1); the basis of determination (wet weight, lipid weight). We added one more variable: animal group (a code to help identify the type of animal: arthropod, bird, fish, mammal, mollusc).

The concentration of the substance in marine organisms is represented by $M_{s, o, m, b}$, (ng/g), and in marine pellets by $P_{s}(\mathrm{ng} / \mathrm{g})$, with $s$ the substance (DDTs, or PCBs), $o$ the organism, $m$ the matrix (see Table 1), and $b$ the indication whether the concentrations are reported as wet weight or lipid-normalized. DDTs includes DDT (p, $\left.\mathrm{p}^{\prime}\right), \operatorname{DDE}\left(\mathrm{p}, \mathrm{p}^{\prime}\right), \operatorname{DDD}\left(\mathrm{p}, \mathrm{p}^{\prime}\right), \operatorname{DDT}\left(\mathrm{o}, \mathrm{p}^{\prime}\right)$, $\operatorname{DDE}\left(\mathrm{o}, \mathrm{p}^{\prime}\right)$, DDD $\left(\mathrm{o}, \mathrm{p}^{\prime}\right)$. PCBs in the Pellet Watch database are the sum 13 congeners IUPAC (nos. CB66, 101, 110, 149, 118, 105, $153,138,128,187,180,170,206)$; while the ICES includes 7 congeners, CB28, 52, 101, 118, 138, 153, 180. The two databases include a different number of congeners which introduces some uncertainty when comparing their results. They are not incompatible for the present study, as is it possible to estimate the intervals for the uncertainty. For instance, the relationship between the standard NOAA list of 18 congeners and a "True" PCB value was investigated (NOAA, 1991, 1989) in sediments and mussels, which concluded that the sum of the 18 congeners amounts to about half of the total PCBs present in the sample. This ratio was confirmed by Lefkovitz et al. (2001) for samples of lobster hepatopancreas. However, in a food web study performed with tree swallows (Tachycineta bicolor) in the Hudson River 
area, New York state, U.S., the sum of seven congeners accounted rather constantly for all biota between 20 and $34 \%$ of the total PCBs. It can be expected, then, that the sum of PCBs provided by Pellet Watch is between 1.5 and 2.5 times higher than that of ICES, or around $0.3 \log$ units.

The dataset for concentrations of DDTs and PCBs in marine pellets was retrieved from the International Pellet Watch (IPW) Global monitoring of OCCs by using beached plastic resin pellets (http://pelletwatch.org/), based in Japan. IPW has been processing samples from all over the world since 2006 (Ogata et al., 2009). The PCB concentration reflects the sum of the 18 congeners mentioned above. A uniform distribution of the different congeners is assumed.

The Kruskal-Wallis non-parametric method was used for comparison of medians, followed, when necessary, by Dunn's post hoc test, with a significance level of $1 \%$. Calculations were made in the $\mathrm{R}$ suite using package FSA. Central tendency statistic is represented by the median and dispersion by the coefficient of interquartile variation (cqv), given by

$$
c q v=\frac{(p 75-p 25)}{(p 75+p 25)}
$$

with p25 and p75 the 25th and 75th percentiles of the data distribution, respectively.

The ratios, $R_{s, o, m, b}$, of concentration of the substance in marine organisms, $M_{s, o, m, b}$, (ng/g) to that in the pellets, $P_{s}(\mathrm{ng} / \mathrm{g})$ was computed by

$$
R_{s, o, m, b}=\frac{\log \mathrm{M}_{s, o, m, b}}{\log \mathrm{P}_{s}}
$$

$\log M$ and $\log P$ are probability density functions estimated from the original dataset. The posterior density, $R$. Given that measurements in pellets and marine organisms come from different sampling locations, measured at different times, they cannot be compared directly. Instead, the statistical distributions of $\mathrm{M}$ and $\mathrm{P}$ were modelled with theoretical statistical distributions followed by repeated random sampling and recomputation of $\mathrm{R}$ (Monte Carlo simulations). Oracle’s Crystal Ball ${ }^{\circledR}$ suite was used to facilitate the computations.

At equilibrium, the partition constant between $P_{s}(\mathrm{ng} / \mathrm{kg})$ and water concentration (free form), $C_{w}(\mathrm{ng} / \mathrm{L})$ is

$$
K_{P}=\frac{\mathrm{P}_{s}}{C_{w}}
$$

The value of $K_{p}$ varies with the properties of each polymer and the affinity of the sorbing substance. Here we use the $K_{P}$ proposed by (Lohmann, 2012) corrected by an ionic strength factor of plus $50 \%$, for a Setschenow (1889) constant of 0.35 (Xie et al., 1997), to convert from freshwater to ocean water. About $90 \%$ of the pellets analysed under the Pellet Watch program were of polyethene (PE) (Ogata et al., 2009), so only the $K_{P E}$ is henceforth used and applied to all pellets. This latter assumption brings in some uncertainty to the analysis. It may be somewhat limited by the fact that long-term sorption coefficients of very hydrophilic substances in the ocean are similar for plastics that constitute the large majority of the found pellets, namely low-density polyethene (LDPE), high-density polyethene (HDPE) and polypropylene (PP) (Rochman et al., 2013; O'Connor et al., 2016; Allen et al., 2018).

Bioconcentration factors (BCF) are calculated by considering contaminant tissue concentrations with respect to environmental water concentrations. BCF $(\mathrm{L} / \mathrm{kg})$ are commonly lipid normalized by accounting for the concentration of lipids in the organism:

$$
B C F=\frac{\left(M_{s, o, m} / V_{L}\right)}{C_{w}}
$$

with $V_{L}$ the fraction of lipid in the organism, and $\mathrm{C}_{\mathrm{w}}$ is the concentration of the substance in seawater (ng/L).

For chemicals that accumulate to a significant extent via diet, bioaccumulation can be estimated from the bioaccumulation factor (BAF) using food chain multipliers (FCM), which for substances with $\log \mathrm{K}_{\mathrm{OW}}$ between 6.0 and 7.5 are 13 and 23-24 for trophic level 3 (planktivorous) and level 4 (piscivorous fish), respectively (Boethling and Mackay, 2000; USEPA, 2000):

$$
B A F=\frac{B C F \cdot F C M}{C_{w}}
$$

The ratio between the estimated bioaccumulation factor and the partition constant $\mathrm{K}_{\mathrm{PE}}$,

$$
R_{s}^{*}=\frac{\log B A F_{s}}{\log K_{P E, s}}
$$

is a theoretical estimate of $R_{s, o, m, l i p i d}$ at chemical equilibrium, therefore $\mathrm{R} \approx \mathrm{R}^{*}$.

\section{RESULTS AND DISCUSSION}

\subsection{OCCs in Marine Organisms}

Data for lipid-normalized DDTs in the ICES database is available for a large number of different organisms and matrices, but statistical analysis showed that they could be aggregated into four statistical populations (Kruskal-Wallis test, K-W $\chi^{2}(3)=$ 1399.1, $\mathrm{p}<2 \times 10^{-16}$, Dunn post hoc test, $p<0.01$ - see Supplementary Material for detailed statistical results), $M_{D D T}$, $o, m$, lipid. They are (Figure 1A; Table 2): 1) bird eggs (EG), with the highest concentrations; followed by 2) liver (LI), 3) muscle (MU), and finally 4) the whole soft body (SB). The differences result from different factors: samples coming from different organisms, with different feeding habits and position in the food web, and measurements made in different matrices (Table 1). To compare accumulation of DDTs in marine organisms and plastic pellets, the mentioned factors were considered separately.

Median concentrations of DDTs in eggs in the dataset are $4.28 \log$ units $(\mathrm{ng} / \mathrm{g})\left(=10^{4.28} \mathrm{ng} / \mathrm{g}\right)$ (Figure 1A; Table 2). At these high concentrations, eggshell thinning has been observed in birds (due to the presence of o,p' DDT). In avian wildlife, thinning can result from a functional malformation in the shell gland, induced by embryonic exposure to estrogenic substances (Holm et al., 2006). Long term effects of eggshell thinning are a 

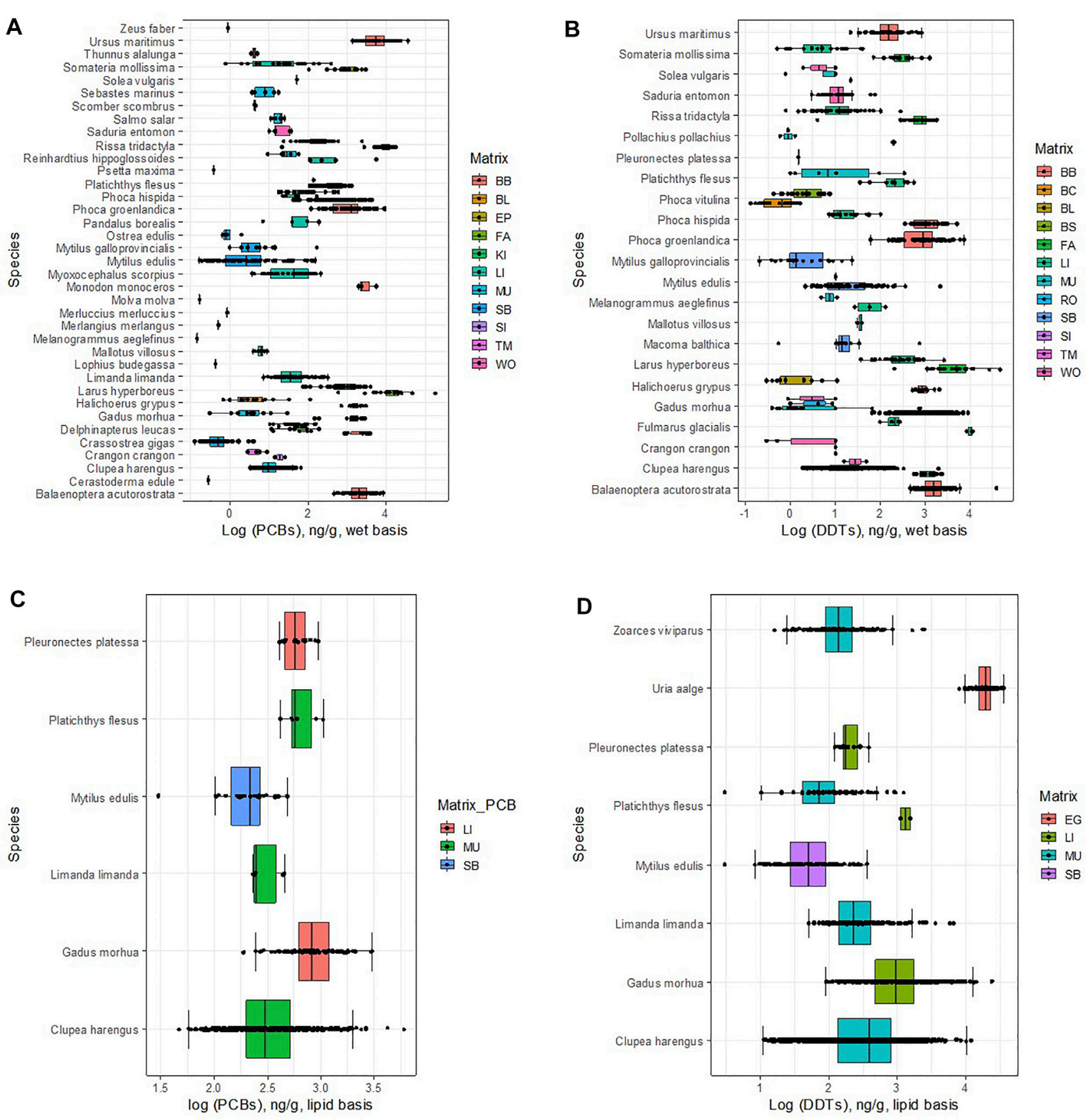

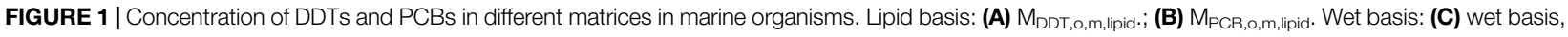
$M_{D D T, o, m, w e t}$; (D) $M_{P C B, o, m, w e t}$. For a list of matrix, codes see Table 1.

drastic decline in the numbers of birds of prey (Mitra et al., 2011). Elevated DDTs concentrations in waterbird eggs have also been found in heavily industrialized marine environments. For instance, in a study in Hong Kong, Wang et al. (2011) found concentrations in the range 3.40-4.21 log units (ng/g), for eggs of the Night Heron (Nycticorax) and the Great Egret (Egretta $a l b a$ ), respectively. In central Canada, values of 5 log units (ng/ g) were reported for Herring gulls (Larus argentatus) (Hellou et al., 2013).
Accumulation of DDTs in the fish liver in the OSPAR region (2.95 log units, $\mathrm{ng} / \mathrm{g}$ ), surpasses by more than one order of magnitude those found in remote places of the planet, as reported by Lana et al. (2014) for Antarctic Trematomus newnesi, Notothenia coriiceps, and Notothenia rossii, which were below $1.4 \log$ units (ng/g); or off Pernambuco, northeastern Brazil, where concentrations of $1.5 \log$ units (ng/g) were found in the liver of king mackerel (Scomberomorus cavalla) (Miranda and Yogui, 2016). 
TABLE 2 | Concentration of DDTs and PCBs in marine organisms ( $\left.M_{s, o, m, b}\right)$.

\begin{tabular}{|c|c|c|c|}
\hline Basis & Matrix (m) & $\begin{array}{c}\text { Organism (group) (o) (Median; interquartile range; } \\
\text { cqv) }\end{array}$ & Sample size, $\mathbf{N}$ \\
\hline \multirow[t]{9}{*}{ Lipid base } & DDTs & & \\
\hline & Eggs (bird) (EG) & Birds (4.28; 0.153 ng/g; 0.02) & 100 \\
\hline & Liver (LI) & Fish (2.95; 0.609 ng/g; 0.01) & 1376 \\
\hline & Muscle (MU) & Fish $(2.47 ; 0.791 \mathrm{ng} / \mathrm{g} ; 0.16)$ & 3538 \\
\hline & Soft whole body (SB) & Mollusc (1.70; 0.513 ng/; 0.15) & 195 \\
\hline & PCBs & & \\
\hline & Liver (LI) & A: Fish (2.90; 0.312 ng/g; 0.05) & 126 \\
\hline & Muscle (MU) & A: Fish (2.48; 0.409 ng/g; 0.08) & 915 \\
\hline & Soft whole body (SB) & A: Mollusc $(2.34 ; 0.267$ ng/g; 0.06) & 39 \\
\hline \multirow{11}{*}{$\begin{array}{l}\text { Wet weight } \\
\text { base }\end{array}$} & DDTs & & \\
\hline & Fat and blubber (FA, BB) & Birds and mammals $(2.97 ; 0.609$ ng/g; 0.10) & $\mathrm{N}($ bird $)=77 ; \mathrm{N}($ mammal $)=279$ \\
\hline & Liver (LI) & $\begin{array}{l}\text { A: Birds and mammals (1.20; } 0.652 \text { ng/g; } 0.37 \text { B: Fish (2.93; } \\
0.430 \mathrm{ng} / \mathrm{g} ; 0.07)\end{array}$ & $N($ bird $)=266 ; N($ mammal $)=45 ; N($ fish $)=1436$ \\
\hline & $\begin{array}{l}\text { Muscle and whole body (MU, } \\
\text { WO, SB) }\end{array}$ & Arthropod, fish, and molluscs (1.18; 0.644 ng/g; 0.27) & $N($ arthropod $)=35 ; N($ fish $)=928 ; N($ mollusc $)=120$ \\
\hline & Blood (BC, BL, BS) & Mammal (0.011; 0.600 ng/g; 4.24) & 56 \\
\hline & $\begin{array}{l}\text { Tail muscle and fish roe } \\
(T M, R O) \\
\text { PCBs }\end{array}$ & Fish (1.00; 0.388 ng/g; 0.18) & 9 , of which 8 are for roe \\
\hline & Fat (FA) & A: Bird (3.97; 0.896 ng/g; 0.09) & 73 \\
\hline & Blubber (BB) & A: Mammals (3.18; 0.661 ng/g; 0.10) & 362 \\
\hline & Liver (LI) & A: Bird, arthropod, fish, and mammal (2.08; 1.09 ng/g; 0.26) & $\begin{array}{l}N((\text { bird })=101 ; N(\text { arthropod })=5 ; N(\text { fish })=226 ; N \\
(\text { mammal })=10\end{array}$ \\
\hline & Muscle and blood (MU, BL) & A: Fish (0.982; 0.340 ng/g) B: Mammal (1.56; 0.852 ng/g; 0.22) & $N($ fish $)=362 ; N($ mammal $)=56$ \\
\hline & Soft whole body (SB) & A: Molluscs (0.167; 0.896 ng/g; 2.26) & $N($ mollusc $)=212$ \\
\hline
\end{tabular}

See Supplementary Material, for detailed statistical results.

Fish muscle samples showed lipid-based DDTs concentrations in the order of $2.47 \mathrm{log}$ units (ng/g), which are similar to those found in other areas with high anthropogenic influence. For instance, Sun et al. (2020) reported values between 1.96 and $2.35 \mathrm{log}$ units of yellowfin tuna (Thunnus albacares) and their prey from the South China Sea. In croakers and mullets collected in Guanabara Bay, Rio de Janeiro and Araújo Island, Paraty, Silva et al. (2016) reported (mean) DDTs concentrations in the range 2.55-3.58 log units (ng/ g). Concentrations in the OSPAR region are, however, one to two orders of magnitude above those found in more pristine regions of the globe. In Antarctica, DDTs (mean) concentrations did not surpass $1.1 \log$ units (ng/g) in Trematomus newnesi, Notothenia coriiceps, and Notothenia rossii (Lana et al., 2014). In Tanzania (western Indian Ocean) median DDTs concentrations found in the muscle of Mtwara milkfish (Chanos) and Pemba mullets (Mugil cephalus) were equal to 0.12 and $1.85 \log$ units (ng(g), respectively (Mwakalapa et al., 2008).

In the OSPAR region, median concentrations in molluscs (mainly bivalves) are less elevated than those found in other equally industrialized regions, such as in the continental coast of the United States where median DDTs in mussels ranged between 2.30 and $2.17 \mathrm{log}$ units (ng/g) (Sericano et al., 2014) (values converted from dry weight using wet weight/dry weight ratios from Ricciardi and Bourget (1998) and lipid content of 1.0\%, following the recommendations of the European Commission: $5 \%$ lipid weight and $26 \%$ dry weight content for fish, and $1 \%$ lipid weight and $8.3 \%$ dry weight content for mussels, for normalizing contaminant concentrations). Yet, OSPAR concentrations are larger than those of more pristine environments, such as
Greenland, where reported (mean) DDTs concentrations in mussels are lower than $1.65 \mathrm{log}$ units (ng/g) (UNEP, 2003).

Molluscs include benthic organisms which have contact with the substrate, making them useful as monitors of local pollution. It has been shown, however, that in situ biomonitoring shows seasonal patterns and environmentally mediated gaping activity in bivalves (Garcia et al., 2016), though it does not seem to impair their capacity to detect temporal trends related to changes in contaminant levels (Zangrandi et al., 2005). Despite these uncertainties, they have been extensively used, for example, as the pioneers in NOAA's Mussel Watch Program launched in 1985-1986 (Farrington et al., 2016). Other similar programs were later implemented throughout the world (Hamilton, 1989; Ramu and Kajiwara, 2007; Knopf et al., 2020). In more recent years, more emphasis is being put on assessing key biomarkers of biological responses to evaluate the health of organisms, linking observed responses to contaminant exposure, as in the European Marine Strategy Framework Directive (Directive 2008/ 56/EC, 17 June 2008). At present, the lack of knowledge on assessment criteria of the biomarker responses in certain target species used in integrated monitoring programmes of marine pollution puts limitations to its generalized use (EC, 2014a).

For PCBs in a lipid basis, three statistical populations were found in the data according to the factor with the highest variance (Kruskal-Wallis chi-squared, K-W $\chi^{2}(2)=179.2, p<2 \times 10^{-16}$, Dunn post hoc test, $p<0.01$-see Supplementary Material for detailed statistical results). The statistically different matrices are, except for bird's eggs, the same as those found for DDTs (Figure 1B; Table 2): 1) liver (LI), with the highest 
concentrations; followed 2) muscle (MU), and finally, 3) the whole soft body (SB). The former two were quantified in fish and the latter in molluscs.

The median concentrations of PCBs found in the liver and muscle of fish are similar to those measured for DDTs (Table 2), namely 2.90 in the liver, and $2.48 \mathrm{log}$ units (ng/g) in muscle, which compare with 2.95 and $2.47 \mathrm{log}$ units (ng/g), respectively for DDTs. Molluscs, on the other hand, show higher median uptake of PCBs (2.34 log units (ng/g)) than of DDTs (1.70 log units (ng/g)). These results are in agreement with the stabilization of the concentrations of these OCCs in the living tissues we report above. The uptake of similar amounts of the two OCCs by fish have been found elsewhere, namely for Salvelinus alpinus, in Bjørnøya Island, Norway (Evenset et al., 2004); for Xiphias gladius in the Azores Archipelago (Stefanelli et al., 2004); for Exocoetus volitans and Sula leucogaster, in São Pedro and São Paulo Archipelago, Brazil (Dias et al., 2013); for Larus dominicanus, in Kerguelen islands, south Indian Ocean (Monod et al., 1992); for Trematomus newnesi, Notothenia coriiceps and Notothenia rossii, in the South Shetland Islands, Antarctica (Lana et al., 2014). DDTs and PCBs metabolites and congeners share similar environmental fate properties, as we discussed in the methods. Considering that the total global mass discharged into the environment may also be similar, then, from a synoptic point of view their environmental concentrations should converge. Of course, this consideration does not apply at a local scale, where particular circumstances gain relevance, as has been demonstrated extensively in the literature (UNEP, 2003). Nor does it apply to molluscs, which due to feeding on phytoplankton or by the filter-feeding of bottom sediments may register a chemical signature in par with that of sediment. The concentrations in the database for PCBs in molluscs are about 0.6 log units above those of DDTs. This may be justified by the fact that in Europe, where DDT has been banned since the eighties, its presence in the sediments is low (though the dataset is still very limited), in the order of 0.05-0.34 ng/g dw ( -1.30 to $-0.47 \mathrm{log}$ units, ng/g) (Pinto et al., 2016); while the levels of PCBs are about two orders of magnitude higher (10 ng/g dw, or $1.0 \mathrm{log}$ unit) (EC, 2010), reflecting the more continuous input into the environment.

Similar to the lipid basis data, four statistical populations were identified in the data for DDT on a wet basis, $M_{D D T, o, m, w e}$, (Kruskal-Wallis test, K-W $\chi^{2}(11)=1680.6, p<2 \times 10^{-16}$, Dunn post hoc test, $p<0.01-$ see Supplementary Material for detailed statistical results). They are: 1) two lipid matrices, fat (FAT) and blubber (BB), with concentrations of DDTs well above the others (Figure 1C; Table 2); 2) the liver matrix (LI), with intermediate-high concentrations; 3 ) followed by the muscle and whole-body matrices (MU, WO, and SB); and 4) finally the blood matrices (BC, BL, and $\mathrm{BS}$ ) with the lowest concentrations. Tail muscle (TM) and fish row (RO) share similar concentrations with the muscle and blood matrices, but the number of samples is still very limited to be statistically relevant. Five statistical populations were identified in the data for PCBs on a wet basis, $\mathrm{M}_{\mathrm{PCB}, \mathrm{o}, \mathrm{m} \text {,wet }}\left(\mathrm{K}-\mathrm{W} \chi^{2}(10)=1105.9, \mathrm{p}<2 \times 10^{-16}\right.$, Dunn post hoc test, $p<0.01-$ see Supplementary Material for detailed statistical results). They are: 1) two lipid matrices, fat (FAT) and blubber (BB), with concentrations of PCBs well above the others (Figure 1; Table 2); followed by 2) the liver matrix (LI); 3) the muscle and blood matrices (MU, BL); and 4) finally the soft whole body (SB) with the lowest concentrations. For the remaining matrices, the number of samples is still too limited to be statistically relevant.

Results for the wet-basis for fish liver mirror those of the lipidbasis, so to compare with passive sampling via plastic pellets they seem to be interchangeable (Table 2) for both DDTs and PCBs. On the contrary, for fish muscle, the concentrations on a wet basis are about $1.5 \log$ units lower than those obtained for the lipid basis. However, the ratio $\log \mathrm{DDTs} / \log \mathrm{PCBs} \approx 1$ is maintained in both the liver and the muscle, again indicating an equal level of exposure/accumulation to both OCCs.

Data on a wet basis for molluscs is undermined by a very high dispersion $(\mathrm{cqv}=2.26$, which contrasts with cqv $<0.35$ for the remaining matrices, except for blood). Lipid-normalizing seems to contribute positively to reducing dispersion, which is at odds with the rationale that the whole body biota concentration is linearly correlated with the lipid content of the species (EC, 2014b). The very different number of samples and the period covered by the two sets (212 samples and 25 years against 39 samples and 8 years, for wet and lipid-basis, respectively) may help justify such incongruence.

The fat of birds, unlike their liver, accumulated more PCBs than DDTs by about one order of magnitude (2.97 log units for DDTs and $3.97 \log$ units for PCBs) (Figure 1D; Table 2). The blubber of mammals, despite being a lipid matrix, seems to accumulate equally in both OCCs (2.97 log units of DDTs and 3.18 log units of PCBs), more in line with the results for the liver. The median concentrations for DDTs are in the range of those found elsewhere (see Figure 1C). For example, Lopez et al. (2012) found (mean) concentrations of $2.36 \log$ units (ng/g) in Hawaiian monk seals (Monachus schauinslandi) in Hawaiian Islands. In Greenland, Polar bears (Ursus maritinus) accumulated $2.51 \mathrm{log}$ units (ng(g). In the same study, the concentration of PCBs (3.70 log units) was, however, higher than that of the most extreme values in the database.

The concentrations of DDTs in blood showed very high variability (cqv $=4.24)$ and median values of only $0.01 \mathrm{log}$ units (Figure 1C; Table 2). For PCB the results are better (cqv $=0.22$ ) for a median of $1.56 \log$ units (Figure 1D; Table 2). The concentrations in the blood are two orders of magnitude lower than in the blubber, results which are coincident with the literature (Gebbink et al., 2008).

The values in the database, as indicated above, reproduce well the published median and range of variability of the studied OCCs in marine organisms, which is a fundamental condition for our subsequent analysis.

\subsection{PES as a Proxy for Bioaccumulation}

Concentrations of OCCs in marine pellets are statistically similar throughout the world for DDTs, and lower in the Indian Ocean for PCBs (Table 3). Therefore, the complete dataset of 263 samples was used in the subsequent analysis for DDTs, while for PCBs data from the Indian Ocean $(N=39)$ were excluded for comparison with data from the OSPAR region, resulting in a total of 344 samples. 
TABLE 3 | Concentration of DDTs and PCBs in marine pellets, $\mathrm{P}_{\mathrm{DDT}}$ and $\mathrm{P}_{\mathrm{PCB}}$ (Log).

\begin{tabular}{|c|c|c|}
\hline $\begin{array}{l}\text { Marine } \\
\text { pellets }\end{array}$ & $\begin{array}{c}\text { Location of sampling } \\
\text { (median; interquartile range; } \\
\text { cqv) }\end{array}$ & $\begin{array}{l}\text { Statistical test (kruskal-wallis), } \\
\text { alpha }=0.01^{\star}\end{array}$ \\
\hline DDTs & $\begin{array}{l}\text { A: Atlantic Ocean, Pacific Ocean, Indic Ocean, North Sea, Mediterranean } \\
\text { Sea }(0.726 \text { ng/g; } 0.917 \text { ng/g; 0.62) }\end{array}$ & $\begin{array}{l}\left.\mathrm{K}-\mathrm{W} \chi^{2} 4\right)=6.35, \mathrm{p}=0.18 \mathrm{~N}(\text { Atl })=86 ; \mathrm{N}(\mathrm{Pac})=114 ; \mathrm{N}(\mathrm{Med})=19 ; \mathrm{N}(\text { North })=11 ; \\
\mathrm{N}(\text { Ind })=33\end{array}$ \\
\hline PCBs & $\begin{array}{l}\text { A: Atlantic Ocean, Pacific Ocean, North Sea, Mediterranean Sea (1.66; } \\
1.15 \text { ng/g; 0.35) }\end{array}$ & $\begin{array}{l}\text { K-W }(4)=41.3, p<0.01 ; \text { followed by Dunn test, significant for Indic OceanN(Atl) } \\
=145 ; \mathrm{N}(\mathrm{Pac})=138 ; \mathrm{N}(\mathrm{Ind})=39 ; \mathrm{N}(\mathrm{Med})=47 ; \mathrm{N}(\text { North })=14\end{array}$ \\
\hline
\end{tabular}
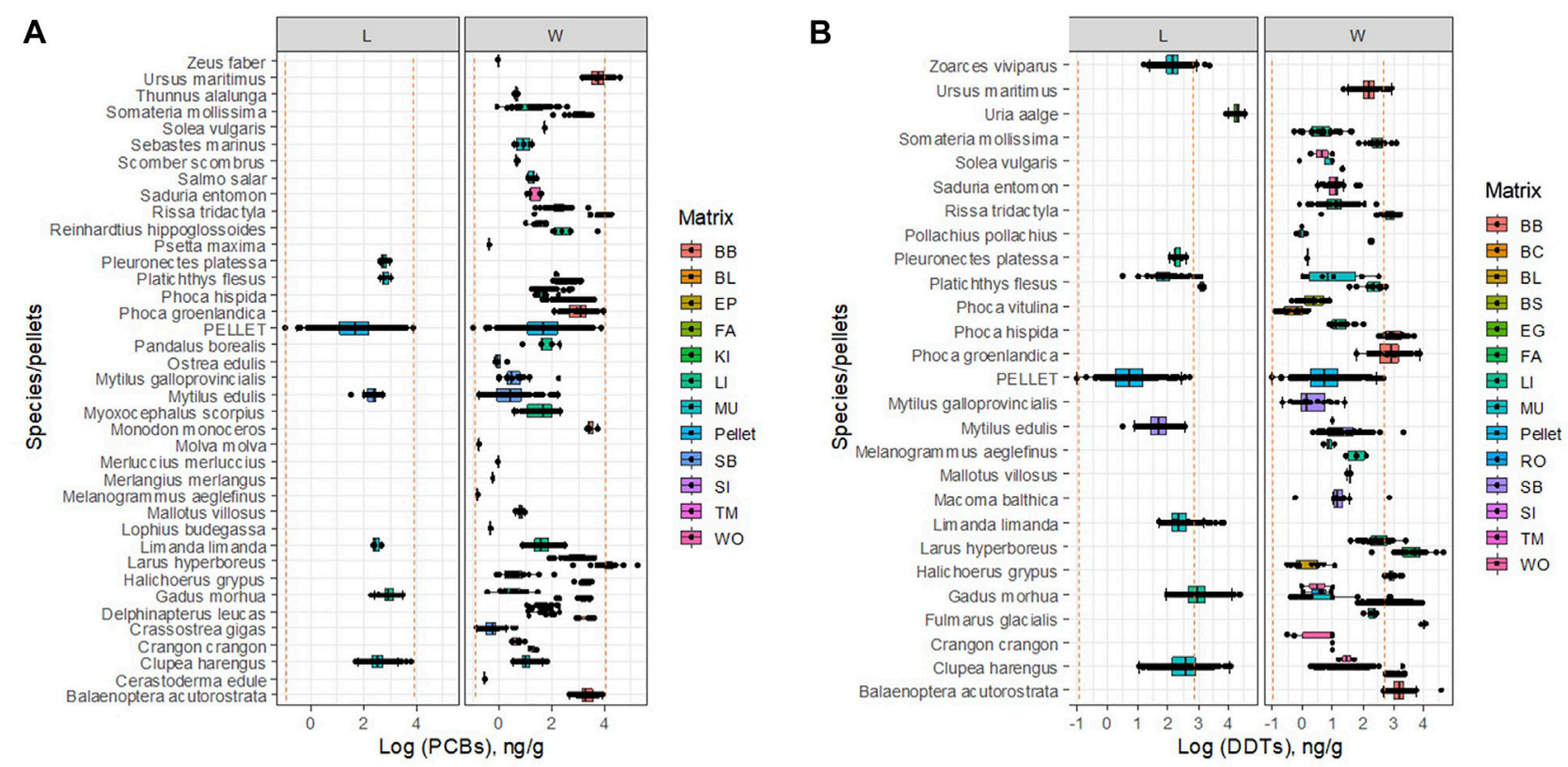

FIGURE 2 | Concentration of PCBs (A) DDTs (B) in marine organisms and marine plastic pellets. L: lipid-normalized; W: wet weight. Vertical lines show a range of concentrations found in.

The concentrations of DDTs in the pellets show high variability, which encompasses in its range most of the concentrations found in non-lipidic matrices in marine organisms when measured as wet weight. On the other hand, concentrations of DDTs in pellets are over two log units lower than those in the lipidic matrices, or in lipid-normalized concentrations in organisms (Figure 2B).

The concentrations of PCBs in marine pellets show again high variability, which encompasses in its range most of the concentrations found in both the wet and lipid-basis of nonlipidic matrices in marine organisms (Figure 2A).

For computing the $R^{\star}$ ratio (Eq. 6), we use bioaccumulation factors for trophic level 4, as available in US EPA EpiSuit, (Eq. 5), are $\log \mathrm{BAF}=6.365 \mathrm{~L} / \mathrm{kg}$ for DDT, and $\log \mathrm{BAF}=6.888 \mathrm{~L} / \mathrm{kg}$ for PCB-153 (USEPA, 2012b). The congener 153 was selected here for being one of the seven congeners frequently measured by the International Council for the Exploration of the Sea (Duinker et al., 1988). Partition coefficients, $K_{\mathrm{PE}}$, for many organic substances were compiled by Lohmann (2012) for freshwater. Following the author's recommendation, we applied a compensation factor of plus $50 \%$ to correct for the decrease of solubility with the increased ionic strength of ocean water. After correction, for DDT, $\log \mathrm{K}_{\mathrm{PE}}=5.98 \mathrm{~L} / \mathrm{kg}$; and for PCB, $\log \mathrm{K}_{\mathrm{PE}}=$ $6.98 \mathrm{~L} / \mathrm{kg}$. The theoretical $\log \mathrm{BAF} / \log \mathrm{K}_{\mathrm{PE}}, R^{\star}$, is then equal to 1.06 and 0.99 , for DDT and PCB, respectively. Interestingly, these estimates agree with recent research comparing passive sampler uptake to bioaccumulation by organisms of lower trophic levels, under the assumption that the passive sampler polymer and the organism lipid have a similar, proportional affinity for a given hydrophobic organic chemical, or $\log \mathrm{M} / \log \mathrm{P} \approx 1$ (Joyce et al., 2016).

As indicated in the Methods, the concentrations of PCBs in marine pellets may differ from those measured in marine organisms by plus $0.3 \mathrm{log}$ units (ng/g) due to the use of different analytical methods. The correction by this amount would alter the estimates of the ratios by less than $+20 \%$ (well lower than the interquartile range), i.e., the magnitude of the output uncertainty due to this cause is much smaller than that of the natural variability. Hence, the difference in analytical methods does not impede the use of the estimated ratios. 
TABLE 4 | Organism-to-pellet DDTs and PCBs ratios, $R_{D D T, o, m, b}$. and $R_{P C B, o, m, b}$

\begin{tabular}{|c|c|c|c|}
\hline \multicolumn{4}{|l|}{ DDTs } \\
\hline Basis (b) & Organism (o) & Matrix (m) & $\begin{array}{c}\mathbf{R}_{\mathrm{s}, \mathrm{o}, \mathrm{m}, \mathrm{b}} \text { (P25; median; } \\
\text { P75; cqv) }\end{array}$ \\
\hline \multirow[t]{4}{*}{ Lipid } & Bird & Eggs (EG) & $2.75 ; 4.64 ; 8.63 ; 0.52$ \\
\hline & Fish & Liver (LI) & $1.86 ; 3.18 ; 5.98 ; 0.53$ \\
\hline & Fish & Muscle (MU) & $1.46 ; 2.60 ; 4.92 ; 0.54$ \\
\hline & Mollusc & Soft whole body (SB) & $0.99 ; 1.78 ; 3.38 ; 0.55$ \\
\hline \multirow[t]{5}{*}{ Wet } & Mammal & Blood (BC, BL, BS) & $-0.40 ; 0.05 ; 0.54 ; 6.68$ \\
\hline & Bird and mammal & Fat and blubber (FA, BB) & $1.79 ; 3.13 ; 5.91 ; 0.53$ \\
\hline & Bird and mammal & Liver (LI) & $0.54 ; 1.31 ; 2.77 ; 0.67$ \\
\hline & Fish & Liver (LI) & $1.86 ; 3.15 ; 5.90 ; 0.52$ \\
\hline & Arthropod, fish, mollusc & Muscle, whole-body (WO, SB) & $0.59 ; 1.23 ; 2.45 ; 0.61$ \\
\hline \multicolumn{4}{|l|}{ PCBs } \\
\hline \multirow[t]{3}{*}{ Lipid } & Fish & Liver (LI) & $1.27 ; 1.66 ; 2.36 ; 0.30$ \\
\hline & Fish & Muscle (MU) & $1.09 ; 1.44 ; 2.05 ; 0.31$ \\
\hline & Mollusc & Soft whole body (SB) & $0.96 ; 1.28 ; 1.83 ; 0.31$ \\
\hline \multirow[t]{6}{*}{ Wet } & Mammal & Blubber (BB) & $1.35 ; 1.80 ; 2,59 ; 0.31$ \\
\hline & Bird & Fat (FA) & $1.63 ; 2.16 ; 3.10 ; 0.31$ \\
\hline & Arthropod, bird, fish, mammal & Liver (LI) & $0.81 ; 1.18 ; 1.77 ; 0.37$ \\
\hline & Fish & Muscle (MU) and blood (BL) & $0.38 ; 0.56 ; 0.85 ; 0.37$ \\
\hline & Mammal & Muscle (MU) and blood (BL) & $0.58 ; 0.89 ; 1.34 ; 0.39$ \\
\hline & Mollusc & Soft whole body (SB) & $-0.13 ; 0.09 ; 0.43 ; 1,92$ \\
\hline
\end{tabular}

In order to compute the ratios $R$ (Eq. 2), estimates of observed organism-to-pellet posterior statistical distributions, $R_{D D T, o, m, b}$ and $R_{P C B, o, m, b}$ were obtained by sampling $10^{5}$ times from the distributions of $\log \mathrm{M}_{D D T, o, m, b}, \log \mathrm{M}_{P C B, o, m, b}$ and $\log \mathrm{P}_{s}$ (see Supplementary Material for details). The percentiles 25, median and 75 were taken from these posterior distributions and the coefficient of quartile variation was computed from the former (Table 4).

Median $R_{D D T, o, m \text {,lipid }}$, for birds and fish in high lipidic matrices are between one and almost four log units above unity (Table 4), which differ substantially from the theoretical ratio $R^{*} \approx 1$. Uptake in fish muscle and liver deviates in the median about two log units from unity (3.18 and 2.60, respectively). Departures from unity have been reported for organochlorine chemicals in high-trophic level consumers. For instance, no relationship was found between uptake by plastic PE samplers and bioaccumulation in some studies (Ellis et al., 1995; Heltsley et al., 2005), while in others the uptake rates of the two matrices were similar within a factor of 2 (Meadows et al., 1998). The ratio for the soft whole body of molluscs shows again a positive deviation from unity (median = 1.78), but in this case, unity is within the interquartile range of the estimated values ( $\mathrm{P} 25=0.99$; P75 $=3.38$ ), which is concordant with other studies for benthic organisms, including molluscs (Joyce et al., 2016).

Similarly to DDTs, concentrations in marine pellets underestimate uptake of PCBs in liver and muscle of fish, but only by about half $\log$ unit $\left(R_{P C B, o, m, l i p i d}=1.66\right.$ and 1.44 , respectively), but the soft whole body of molluscs shows again good agreement with $R^{*}$ (median $=1.28 ; \mathrm{P} 25=0.96$ and $\mathrm{P} 75=$ 1.83) (Table 4). These latter results are in contradiction of those obtained by (Ogata et al., 2009), where they found that PCB concentrations in the beached resin pellets from locations around the world underestimated those found in mussels, though their sample size was much smaller.
The ratios for wet basis, $R_{D D T, o, m, w e t}$ show that the plastic pellets tend to underestimate uptake of DDTs in some matrices by a factor of two, including the fat of birds and blubber of mammals, and the liver of fish (3.13, and 3.15, respectively. Interestingly, the ratio for the liver of birds and mammals (1.31), and the whole body of arthropods, fish and molluscs $(\mathrm{R}=1.23)$ show good agreement between uptake by organisms and marine pellets, encompassing unity within the interquartile range.

The $R_{P C B, o, m, w e t}$ for PCBs in the fat of birds and blubber of mammals are about one log unit above unity, indicating again the underestimation made by marine pellets (1.80, and 2.16, respectively), though smaller than for DDTs. There is a very good match between uptakes for the liver of arthropods, birds, fish and mammals (ratio $=1.18$ ), and the muscle and blood matrices of mammals (0.89). On the other hand, the ratio is lower than unity for muscle and blood matrices of fish (0.56), and the soft whole body of molluscs (0.09).

Several reasons may justify the wide range of $R$ ratios and their deviation from unity. The assumption $\log \mathrm{BAF} \approx \log \mathrm{PE}$ is valid when $\mathrm{PE}$ and the organism's lipids share similar, and proportional, affinity for a given hydrophobic organic chemical, which may not hold due to several reasons. For instance, bioconcentration for PCBs is expected to increase with an increase in chlorine substitution and a decrease in water solubility (Hawker and Connell, 1988; Jonker and Van Der Heijden, 2007), but due to lower uptake rates, the inverse may happen (Porte and Albaigés, 1994; Bremle et al., 1995; WHO, 2003). The elimination of PCBs from aquatic organisms is both species- and congener-specific: congeners containing two vicinal hydrogen atoms at the meta and para positions in at least one aromatic ring are easily metabolized (Pruell et al., 1993); the PCB congeners $110,138,149,153$, and 187 are most recalcitrant in 
mussels; congeners $138,153,170$, and 180 in crabs; $138,153,170$, 180 , and 187 those most recalcitrant in mullet; and $84,110,118$, and 138 those in tuna (Porte and Albaigés, 1994). So, the PCB congeners with the highest tendency to bioaccumulate are the moderately chlorinated (penta-, hexa-, and heptachlorobiphenyls)-which were those synthesized in higher proportions in Aroclor formulations, likely being the most prevalent in the environment. More highly chlorinated OCCs are more tightly bound with soils and sediments, being less bioavailable. Bioaccumulation of OCCs is affected by the water zone in which the organisms reside and feed. For instance, the OCCs levels may be many times higher in the surface strata than in deeper water, and in the sediments, resulting in bioaccumulation levels in fish and bottom-feeding species several times higher in these zones (Södergren et al., 1990). Also, concentrations of persistent organic pollutants in the open ocean are often lower than those observed in coastal areas (Iwata et al., 1993; Schulz-Bull et al., 1998) although they may represent an important part of the global inventory due to a larger oceanic volume (UNECE, 2010).

Another reason for the lower concentrations found in marine pellets may be due to the time of immersion which is insufficient to attain chemical equilibrium and/or for the OCCs to diffuse homogeneously into the plastic pellet. Consider that the partition into the plastic is a first-order equilibrium process described by $P_{s, t}=P_{s, e q}\left(1-\mathrm{e}^{-k t}\right)$, where $P_{s, t}$ is the concentration of the substance (ng/g), in the pellet at time $t$ (month), $P_{s \text {, eq }}$ is the equilibrium concentration (ng/g), $k$ is the sorption rate constant $\left(\mathrm{month}^{-1}\right)$. The latter is equal to 0.1 for high-density polyethene (HDPE) pellets, and 0.2 for low-density polyethene (LDPE) and polypropylene (PP) pellets (Rochman et al., 2013). The sorption rate seems to hold for quite different concentration ranges. For instance, in a study of sorption of $3,3^{\prime}, 4,4^{\prime}$-tetrachlorobiphenyl (PCB77) in PP, in ocean water with concentrations three orders of magnitude above those of Rochman et al., Zhan et al. (2016) found a $\mathrm{k}=0.24$. The equilibrium concentrations, $P_{s, e q}$, on the other hand, are highly variable according to published studies (as e.g., those above cited, as well as the fact that concentrations of OCCs in the database show very high variability), indicating that for low concentrations only quasi-equilibrium is attained. The process of sorption of non-polar organics in plastic pellets in the environment is still surrounded by much uncertainty. For instance, weathering of plastics increase surface area due to the formation of rougher surfaces and opening of cracks, which will increase sorption (Mato and Isobe, 2001); but the formation of oxygen-containing groups such as ketone or esters, while increasing the affinity for polar organics, decrease that for non-polar (Fotopoulou and Karapanagioti, 2012). The two effects seem to counterbalance each other (Endo et al., 2005). Degradation rates of the surface of pellets in the ocean are very slow for $\mathrm{PE}$ and $\mathrm{PP}$, of around 1-3 $\mu \mathrm{m}$ /year (Chamas et al., 2020). The long-term accumulation of organics found in natural conditions may be due to the slow diffusion toward the interior of the material. If that is the case, the concentration would decrease centripetally, eventually becoming zero after some depth from the surface. In that case, the concentrations measured in whole marine pellets would reflect the averaged concentration, including the volume where organics have accumulated as well as the volume of plastic where concentration is zero.

Marine pellets, as well as other synthetic passive samplers, cannot reproduce the processes of food-web biomagnification, which alone can produce up to five log units increase in the lipid-normalized concentration of a bioaccumulative substance (Gobas, 2008). Hence, the ratios here estimated may be useful at screening-level assessments, when detailed data is still missing and high degrees of uncertainty are acceptable (USEPA, 2019).

Beached polyethene marine pellets uptake less OCCs than some organic tissues. The median concentrations of OCCs in the different matrices of fish, birds and mammals are between one to four orders of magnitude higher than those found in marine pellets when lipid-normalized; or up to two orders of magnitude when measured as wet weight. On the other hand, DDTs and PCBs lipid-normalized concentrations and variability in beached marine pellets were similar to those found in molluscs, which agrees with previous studies using passive polyethene samplers (Figueiredo et al., 2017).

Though it is recognized that passive sampling provides information that can be used accurately to predict environmental concentrations (Lohmann and Muir, 2010), some scientific challenges still exist. First, chemical equilibrium between water and the plastic sorbent for high molecular weight apolar organics, such as DDTs and PCBs, can take several months to be attained (Lohmann and Muir, 2010). Second, polyethene samplers have been found to emulate the body burden of benthic biota (Vinturella et al., 2004; Boehm et al., 2005; Fernandez and Gschwend, 2015), but in many cases passive sampling-based concentrations resulted in log BAF - log KEP predictive relationships which were within one to two orders of magnitude of measured bioaccumulation (Joyce et al., 2016). Third, biomagnification at each trophic interaction can lead to food web magnification, often resulting in high concentrations in top predators, which cannot be assessed by a single passive sampling system. Fourth, tissue lipids are often the main factor determining the accumulation of hydrophobic organic contaminants in aquatic organisms (USEPA, 2012c), which again cannot be assessed by a single sampling system. Fifth, pellets are exposed to air when beached, while most of the analysed biota are not. Sixth, the lack of certified reference materials, prohibits the use of commonly agreed values for water-polymer partition and polymer diffusion coefficients (Taylor et al., 2019).

\section{CONCLUSION}

While acknowledging all the uncertainties mentioned above beached marine plastic pellets may still be considered as part of a synoptic non-biological early warning system, but for organisms other than molluscs, correction of concentrations should be made, namely by using the ratios estimated here.

Future research should focus on reducing the many sources of uncertainty listed in this article, in particular by 1) homogenization of chemical procedures; 2 ) better assessment of chemical partition 
equilibrium between water and polymers in environmental conditions; 3) use of (multi) polymer passive samplers better aimed at mimicking uptake by particular matrices.

\section{DATA AVAILABILITY STATEMENT}

Publicly available datasets were analyzed in this study. This data can be found here: https://data.ices.dk/, http://pelletwatch.org/.

\section{AUTHOR CONTRIBUTIONS}

The author confirms being the sole contributor of this work and has approved it for publication.

\section{REFERENCES}

Boehm, P. D., Page, D. S., Brown, J. S., Neff, J. M., and Edward Bence, A. (2005). Comparison of Mussels and Semi-permeable Membrane Devices as Intertidal Monitors of Polycyclic Aromatic Hydrocarbons at Oil Spill Sites. Mar. Pollut. Bull. 50, 740-750. doi:10.1016/j.marpolbul.2005.02.002

Boethling, R. S., and Mackay, D. (2000). Handbook of Property Estimation Methods for Chemicals: Environmental Health Sciences. Boca Raton, FL, USA: CRC Press.

Bremle, G., Okla, L., and Larsson, P. (1995). Uptake of PCBs in Fish in a Contaminated River System: Bioconcentration Factors Measured in the Field. Environ. Sci. Technol. 29, 2010-2015. doi:10.1021/es00008a020

Cerveny, D., Grabic, R., Fedorova, G., Grabicova, K., Turek, J., Kodes, V., et al. (2016). Perfluoroalkyl Substances in Aquatic Environment-Comparison of Fish and Passive Sampling Approaches. Environ. Res. 144, 92-98. doi:10.1016/ j.envres.2015.11.010

Chamas, A., Moon, H., Zheng, J., Qiu, Y., Tabassum, T., Jang, J. H., et al. (2020). Degradation Rates of Plastics in the Environment. ACS Sustain. Chem. Eng. 8, 3494-3511. doi:10.1021/acssuschemeng.9b06635

da Silva, A. M. F., Pavesi, T., Rosa, A. C. S., Santos, T. P. d., de Medeiros Tabalipa, M., Lemes, V. R. R., et al. (2016). Organochlorines and Polychlorinated Biphenyl Environmental Pollution in South Coast of Rio De Janeiro State. Mar. Pollut. Bull. 108, 325-331. doi:10.1016/j.marpolbul.2016.03.067

Dias, P. S., Cipro, C. V. Z., Taniguchi, S., and Montone, R. C. (2013). Persistent Organic Pollutants in marine Biota of São Pedro and São Paulo Archipelago, Brazil. Mar. Pollut. Bull. 74, 435-440. doi:10.1016/j.marpolbul.2013.06.025

Duinker, J. C., Schultz, D. E., and Petrick, G. (1988). Selection of Chlorinated Biphenyl Congeners for Analysis in Environmental Samples. Mar. Pollut. Bull. 19, 19-25. doi:10.1016/0025-326X(88)90748-5

Ec (2010). A Compilation of Europe-wide Databases from Published Measurements of PCBs, Dioxins and Furans. Bruxels, Belgium: European Commission. doi:10.2788/66521

Ec (2014b). Guidance Document No. 32 on Biota Monitoring (The Implementation of EQSbiota) under the Water Framework Directive Common. Technical Report - 2014 - 083. doi:10.2779/833200

Ec (2014a). Joint Research Centre. in European Commission. Brussels, Belgium: Institute for Environment and Sustainability. doi:10.2788/70344Technical Guidance on Monitoring for the Marine Strategy Framework Directive

EEA (2003). Hazardous Substances in the European marine Environment : Trends in Metals and Persistent Organic Pollutants. Copenhagen, Denmark: European Environment Agency.

EEA (2019). The European Environment-State and Outlook 2020. Knowledge for Transition to a Sustainable Europe, Teruleti Statisztika. Luxembourg: European Environment Agency, Publications Office of the European Union. doi:10.15196/TS600305

Ellis, G. S., Rostad, C. E., Huckins, J. N., Schmitt, C. J., Petty, J. D., and Maccarthy, P. (1995). Evaluation of Lipid-Containing Semipermeable Membrane Devices

\section{FUNDING}

Support for the present study was provided through the Portuguese Strategic Plan for the Ocean 2020, European Maritime and Fisheries Fund (EMFF), under the project "Implementation of an action plan to safeguard the seahorse populations in Ria Formosa, by minimizing the existing impacts, protecting and improving the preferred habitats, for controlled restocking," MAR-01.04.02-FEAMP-0029 (2019).

\section{SUPPLEMENTARY MATERIAL}

The Supplementary Material for this article can be found online at: https://www.frontiersin.org/articles/10.3389/fenvs.2021.784317/ full\#supplementary-material

for Monitoring Organochlorine Contaminants in the Upper Mississippi River. Environ. Toxicol. Chem. 14, 1875-1884. doi:10.1002/etc.5620141109

Endo, S., Takizawa, R., Okuda, K., Takada, H., Chiba, K., Kanehiro, H., et al. (2005). Concentration of Polychlorinated Biphenyls (PCBs) in Beached Resin Pellets: Variability Among Individual Particles and Regional Differences. Mar. Pollut. Bull. 50, 1103-1114. doi:10.1016/j.marpolbul.2005.04.030

Evenset, A., Christensen, G. N., Skotvold, T., Fjeld, E., Schlabach, M., Wartena, E., et al. (2004). A Comparison of Organic Contaminants in Two High Arctic lake Ecosystems, Bjørnøya (Bear Island), Norway. Sci. Total Environ. 318, 125-141. doi:10.1016/S0048-9697(03)00365-6

Farrington, J. W., Tripp, B. W., Tanabe, S., Subramanian, A., Sericano, J. L., Wade, T. L., et al. (2016). Edward D. Goldberg's Proposal of "the Mussel Watch": Reflections after 40 Years. Mar. Pollut. Bull. 110, 501-510. doi:10.1016/ j.marpolbul.2016.05.074

Fernandez, L. A., and Gschwend, P. M. (2015). Predicting Bioaccumulation of Polycyclic Aromatic Hydrocarbons in Soft-Shelled Clams (Mya arenaria) Using Field Deployments of Polyethylene Passive Samplers. Environ. Toxicol. Chem. 34, 993-1000. doi:10.1002/etc.2892

Figueiredo, K., Mäenpää, K., Lyytikäinen, M., Taskinen, J., and Leppänen, M. T. (2017). Assessing the Influence of Confounding Biological Factors when Estimating Bioaccumulation of PCBs with Passive Samplers in Aquatic Ecosystems. Sci. Total Environ. 601-602, 340-345. doi:10.1016/ j.scitotenv.2017.05.140

Fotopoulou, K. N., and Karapanagioti, H. K. (2012). Surface Properties of Beached Plastic Pellets. Mar. Environ. Res. 81, 70-77. doi:10.1016/ j.marenvres.2012.08.010

Garcia-March, J. R., Jiménez, S., Sanchis, M. A., Monleon, S., Lees, J., Surge, D., et al. (2016). In Situ biomonitoring Shows Seasonal Patterns and Environmentally Mediated Gaping Activity in the Bivalve, Pinna Nobilis. Mar. Biol. 163, 1-12. doi:10.1007/s00227-016-2812-3

Gebbink, W. A., Sonne, C., Dietz, R., Kirkegaard, M., Born, E. W., Muir, D. C. G., et al. (2008). Target Tissue Selectivity and Burdens of Diverse Classes of Brominated and Chlorinated Contaminants in Polar Bears (Ursus maritimus) from East Greenland. Environ. Sci. Technol. 42, 752-759. doi:10.1021/es071941f

Gobas, F. A. P. C. (2008). "Food-Web Bioaccumulation Models," in Encyclopedia of Ecology, Five-Volume Set. Editors S. Jorgensen and B. Fath (New YorkNew York: Oxford University PressOxford University Press), 1643-1652. doi:10.1016/B978-008045405-4.00398-0

Hamilton, E. I. (1989). Chemical Contamination of French Coasts. Mar. Pollut. Bull. 20, 523-528. doi:10.1016/0025-326x(89)90396-2

Hawker, D. W., and Connell, D. W. (1988). Octanol-Water Partition Coefficients of Polychlorinated Biphenyl Congeners. Environ. Sci. Technol. 22, 382-387. doi:10.1021/es00169a004

Hellou, J., Lebeuf, M., and Rudi, M. (2013). Review on DDT and Metabolites in Birds and Mammals of Aquatic Ecosystems. Environ. Rev. 21, 53-69. doi:10.1139/er-2012-0054 
Heltsley, R. M., Cope, W. G., Shea, D., Bringolf, R. B., Kwak, T. J., and Malindzak, E. G. (2005). Assessing Organic Contaminants in Fish: Comparison of a Nonlethal Tissue Sampling Technique to mobile and Stationary Passive Sampling Devices. Environ. Sci. Technol. 39, 7601-7608. doi:10.1021/es051037s

Holm, L., Blomqvist, A., Brandt, I., Brunström, B., Ridderstråle, Y., and Berg, C. (2006). Embryonic Exposure to O,p'-Ddt Causes Eggshell Thinning and Altered Shell Gland Carbonic Anhydrase Expression in the Domestic Hen. Environ. Toxicol. Chem. 25, 2787-2793. doi:10.1897/05-619R.1

Hornsby, A. G., Wauchope, D. R., and Herner, A. E. (1996). Pesticide Properties in the Environment. New York: Springer.

ICES (2013). Report of the Workshop on the Application of Passive Sampling and Passive Dosing to Contaminants in Marine Media. Copenhagen, Denmark: International Council for the Exploration of the Sea.

Iwata, H., Tanabe, S., Sakai, N., and Tatsukawa, R. (1993). Distribution of Persistent Organochlorines in the Oceanic Air and Surface Seawater and the Role of Ocean on Their Global Transport and Fate. Environ. Sci. Technol. 27, 1080-1098. doi:10.1021/es00043a007

Jonker, M. T. O., and Van Der Heijden, S. A. (2007). Bioconcentration Factor Hydrophobicity Cutoff: An Artificial Phenomenon Reconstructed. Environ. Sci. Technol. 41, 7363-7369. doi:10.1021/es0709977

Joyce, A. S., Portis, L. M., Parks, A. N., and Burgess, R. M. (2016). Evaluating the Relationship between Equilibrium Passive Sampler Uptake and Aquatic Organism Bioaccumulation. Environ. Sci. Technol. 50, 11437-11451. doi:10.1021/acs.est.6b03273

Knopf, B., Fliedner, A., Radermacher, G., Rüdel, H., Paulus, M., Pirntke, U., et al. (2020). Seasonal Variability in Metal and Metalloid Burdens of Mussels: Using Data from the German Environmental Specimen Bank to Evaluate Implications for Long-Term Mussel Monitoring Programs. Environ. Sci. Eur. 32, 1-13. doi:10.1186/s12302-020-0289-7

Lana, N. B., Berton, P., Covaci, A., Ciocco, N. F., Barrera-oro, E., Atencio, A., et al. (2014). Fingerprint of Persistent Organic Pollutants in Tissues of Antarctic Notothenioid Fish. Sci. Total Environ. 499, 89-98. doi:10.1016/ j.scitotenv.2014.08.033

Lefkovitz, L. F., Neff, J. M., Lizotte, R., and Hall, R. (2001). Comparison of Two Analytical Methods for Measurement of Chlorinated Pesticides and PCB Congeners in Biological Tissue-Trends in Boston Harbor Lobster Tissue. Boston, USA: Massachusetts Water Resources Authority.

Lohmann, R. (2012). Critical Review of Low-Density Polyethylene's Partitioning and Diffusion Coefficients for Trace Organic Contaminants and Implications for its Use as a Passive Sampler. Environ. Sci. Technol. 46, 606-618. doi:10.1021/ es202702y

Lohmann, R., and Muir, D. (2010). Global Aquatic Passive Sampling (AQUAGAPS): Using Passive Samplers to Monitor POPs in the Waters of the World. Environ. Sci. Technol. 44, 860-864. doi:10.1021/es902379g

Lopez, J., Boyd, D., Ylitalo, G. M., Littnan, C., and Pearce, R. (2012). Persistent Organic Pollutants in the Endangered Hawaiian Monk Seal (Monachus Schauinslandi) from the Main Hawaiian Islands. Mar. Pollut. Bull. 64, 2588-2598. doi:10.1016/j.marpolbul.2012.07.012

Mansouri, A., Cregut, M., Abbes, C., Durand, M.-J., Landoulsi, A., and Thouand, G. (2017). The Environmental Issues of DDT Pollution and Bioremediation: a Multidisciplinary Review. Appl. Biochem. Biotechnol. 181, 309-339. doi:10.1007/s12010-016-2214-5

Mato, Y., Isobe, T., Takada, H., Kanehiro, H., Ohtake, C., and Kaminuma, T. (2001). Plastic Resin Pellets as a Transport Medium for Toxic Chemicals in the Marine Environment. Environ. Sci. Technol. 35, 318-324. doi:10.1021/ es0010498

Meadows, J. C., Echols, K. R., Huckins, J. N., Borsuk, F. A., Carline, R. F., and Tillitt, D. E. (1998). Estimation of Uptake Rate Constants for PCB Congeners Accumulated by Semipermeable Membrane Devices and Brown Trout (Salmo trutta). Environ. Sci. Technol. 32, 1847-1852. doi:10.1021/es970850n

Miranda, D. A., and Yogui, G. T. (2016). Polychlorinated Biphenyls and Chlorinated Pesticides in king Mackerel Caught off the Coast of Pernambuco, Northeastern Brazil: Occurrence, Contaminant Profile, Biological Parameters and Human Intake. Sci. Total Environ. 569-570 (570), 1510-1516. doi:10.1016/j.scitotenv.2016.06.241

Mitra, A., Chatterjee, C., and Mandal, F. B. (2011). Synthetic Chemical Pesticides and Their Effects on Birds. Res. J. Environ. Toxicol. 5, 81-96. doi:10.3923/ rjet.2011.81.96
Monod, J.-L., Arnaud, P. M., and Arnoux, A. (1992). The Level of Pollution of Kerguelen Islands Biota by Organochlorine Compounds during the Seventies. Mar. Pollut. Bull. 24, 626-629. doi:10.1016/0025-326X(92)90285-E

Mwakalapa, E. B., Mmochi, A. J., Müller, M. H. B., Mdegela, R. H., Lyche, J. L., Polder, A., et al. (2018). Occurrence and Levels of Persistent Organic Pollutants (POPs) in Farmed and Wild marine Fish from Tanzania. A Pilot Study. Chemosphere 191, 438-449. doi:10.1016/j.chemosphere.2017.09.121

NOAA (1991). Second Summary of Data on Chemical Contaminants in Sediments from the National Status and Trends Program, 59. (Washington, DC: NOAA Technical Memorandum NOS OMA).

NOAA (1989). NOAA Technical Memorandum NOS OMA 49. Maryland: National Oceanic and Atmospheric AdministrationEUA.

O'Connor, I. A., Golsteijn, L., and Hendriks, A. J. (2016). Review of the Partitioning of Chemicals into Different Plastics: Consequences for the Risk Assessment of marine Plastic Debris. Mar. Pollut. Bull. 113, 17-24. doi:10.1016/ j.marpolbul.2016.07.021

Ogata, Y., Takada, H., Mizukawa, K., Hirai, H., Iwasa, S., Endo, S., et al. (2009). International Pellet Watch: Global Monitoring of Persistent Organic Pollutants (POPs) in Coastal Waters. 1. Initial Phase Data on PCBs, DDTs, and HCHs. Mar. Pollut. Bull. 58, 1437-1446. doi:10.1016/j.marpolbul.2009.06.014

Ospar Comission (2018). OSPAR Background Document on Pre-production Plastic Pellets Environmental Impacts of Human Activites. London. UK: Convention for the Protection of the Marine Environment of the North-East Atlantic.

Pinto, M. I., Burrows, H. D., Sontag, G., Vale, C., and Noronha, J. P. (2016). Priority Pesticides in Sediments of European Coastal Lagoons: A Review. Mar. Pollut. Bull. 112, 6-16. doi:10.1016/j.marpolbul.2016.06.101

Porte, C., and Albaigs, J. (1994). Bioaccumulation Patterns of Hydrocarbons and Polychlorinated Biphenyls in Bivalves, Crustaceans, and Fishes. Arch. Environ. Contam. Toxicol. 26, 273-281. doi:10.1007/BF00203552

Pruell, R. J., Rubinstein, N. I., Taplin, B. K., LiVolsi, J. A., and Bowen, R. D. (1993). Accumulation of Polychlorinated Organic Contaminants from Sediment by Three Benthic marine Species. Arch. Environ. Contam. Toxicol. 24, 290-297. doi:10.1007/BF01128727

Ramu, K., Kajiwara, N., Sudaryanto, A., Isobe, T., Takahashi, S., Subramanian, A., et al. (2007). Asian Mussel Watch Program: Contamination Status of Polybrominated Diphenyl Ethers and Organochlorines in Coastal Waters of Asian Countries. Environ. Sci. Technol. 41, 4580-4586. doi:10.1021/es070380p

Ricciardi, A., and Bourget, E. (1998). Weight-to-weight Conversion Factors for marine Benthic Macroinvertebrates. Mar. Ecol. Prog. Ser. 163, 245-251. doi:10.3354/meps163245

Rochman, C. M., Hoh, E., Hentschel, B. T., and Kaye, S. (2013). Long-term Field Measurement of Sorption of Organic Contaminants to Five Types of Plastic Pellets: Implications for Plastic marine Debris. Environ. Sci. Technol. 47, 130109073312009-1654. doi:10.1021/es303700s

Rusina, T. P., Carlsson, P., Vrana, B., and Smedes, F. (2017). Equilibrium Passive Sampling of POP in Lipid-Rich and Lean Fish Tissue: Quality Control Using Performance Reference Compounds. Environ. Sci. Technol. 51, 11250-11257. doi:10.1021/acs.est.7b03113

Schulz-Bull, D. E., Petrick, G., Bruhn, R., and Duinker, J. C. (1998). Chlorobiphenyls (PCB) and PAHs in Water Masses of the Northern North Atlantic. Mar. Chem. 61, 101-114. doi:10.1016/S0304-4203(98)00010-3

Scrimshaw, M. D., and Lester, J. N. (1996). The Occurrence and Effects of Organic Micropollutants in Salt Marsh Sediments with Reference to the uk essex Coast: A Review. Environ. Technol. 17, 951-964. doi:10.1080/09593331708616464

Semeena, V. S., and Lammel, G. (2005). The Significance of the Grasshopper Effect on the Atmospheric Distribution of Persistent Organic Substances. Geophys. Res. Lett. 32, a-n. doi:10.1029/2004GL022229

Sericano, J. L., Wade, T. L., Sweet, S. T., Ramirez, J., and Lauenstein, G. G. (2014). Temporal Trends and Spatial Distribution of DDT in Bivalves from the Coastal marine Environments of the continental United States, 1986-2009. Mar. Pollut. Bull. 81, 303-316. doi:10.1016/j.marpolbul.2013.12.049

Setschenow, J. (1889). Über die Konstitution der Salzlösungen auf Grund ihres Verhaltens zu Kohlensäure. Z. für Physikalische Chem. 4U 4U, 117-125. doi:10.1515/zpch-1889-0409

Shi, J., Sanganyado, E., Wang, L., Li, P., Li, X., and Liu, W. (2020). Organic Pollutants in Sedimentary Microplastics from Eastern Guangdong: Spatial Distribution and Source Identification. Ecotoxicology Environ. Saf. 193, 110356. doi:10.1016/j.ecoenv.2020.110356 
Södergren, A., Larsson, P., Knulst, J., and Bergqvist, C. (1990). Transport of Incinerated Organochlorine Compounds to Air, Water, Microlayer, and Organisms. Mar. Pollut. Bull. 21, 18-24. doi:10.1016/0025-326X(90)90147-Z

Stefanelli, P., Ausili, A., Di Muccio, A., Fossi, C., Di Muccio, S., Rossi, S., et al. (2004). Organochlorine Compounds in Tissues of Swordfish (Xiphias Gladius) from Mediterranean Sea and Azores Islands. Mar. Pollut. Bull. 49, 938-950. doi:10.1016/j.marpolbul.2004.06.019

Sun, R.-X., Sun, Y., Xie, X.-D., Yang, B.-Z., Cao, L.-Y., Luo, S., et al. (2020). Bioaccumulation and Human Health Risk Assessment of DDT and its Metabolites (DDTs) in Yellowfin Tuna (Thunnus albacares) and Their Prey from the South China Sea. MARINE POLLUTION BULLETIN 158, 111396. doi:10.1016/j.marpolbul.2020.111396

T, A., S, F., J, D., C, C., and B, P. (2018). Variations in Sorption of Organochlorine Pesticides and PCBs across Six Different Plastic Polymers. J. Environ. Toxicol. Stud. 2, 1-6. doi:10.16966/2576-6430.109

Taylor, A. C., Fones, G. R., Vrana, B., and Mills, G. A. (2019). Applications for Passive Sampling of Hydrophobic Organic Contaminants in Water-A Review. Crit. Rev. Anal. Chem. 51, 20-54. doi:10.1080/10408347.2019.1675043

UNECE (2010). Hemispheric Transport of Air Pollution. Persistent Organic Pollutants. Geneva, Switzerland: United Nations Environment Program.

UNEP (2003). Regionally Based Assessment of Persistent Toxic substancesReport 2003. Switzerland: United Nations Environment Programme, Châtelaine.

USEPA (2012b). EpiWeb Suite.

USEPA (2019). Guidelines for Human Exposure Assessment Guidelines for Human Exposure Assessment. Washington, D. C., U.S.A: United States Environmental Protection Agency.

USEPA (2012a). Guidelines for Using Passive Samplers to Monitor Organic Contaminants at Superfund Sediment Sites. Washington, D. C., U.S.A: United States Environmental Protection Agency.

USEPA (2012c). Guidelines for Using Passive Samplers to Monitor Organic Contaminants at Superfund Sediment sitesOSWER Directive 9200.1-110 FS. Washington, D. C., U.S.A: United States Environmental Protection Agency.

USEPA (2000). Methodology for Deriving Ambient Water Quality Criteria for the Protection of Human Health. Washington, D. C., U.S.A: United States Environmental Protection Agency.

Van Den Berg, H., Manuweera, G., and Konradsen, F. (2017). Global Trends in the Production and Use of DDT for Control of Malaria and Other Vector-Borne Diseases. Malar. J. 16, 1-8. doi:10.1186/s12936-017-2050-2

Vinturella, A. E., Burgess, R. M., Coull, B. A., Thompson, K. M., and Shine, J. P. (2004). Use of Passive Samplers to Mimic Uptake of Polycyclic Aromatic
Hydrocarbons by Benthic Polychaetes. Environ. Sci. Technol. 38, 1154-1160. doi:10.1021/es034706f

Vrana, B., Allan, I. J., Greenwood, R., Mills, G. a., Dominiak, E., Svensson, K., et al. (2005). Passive Sampling Techniques for Monitoring Pollutants in Water. Trac Trends Anal. Chem. 24, 845-868. doi:10.1016/j.trac.2005.06.006

Wang, Y., Murphy, M. B., Lam, J. C. W., Jiao, L., Wong, C. C. L., Yeung, L. W. Y., et al. (2011). Polychlorinated Biphenyls and Organochlorine Pesticides in Local Waterbird Eggs from Hong Kong: Risk Assessment to Local Waterbirds. Chemosphere 83, 891-896. doi:10.1016/ j.chemosphere.2011.02.073

WHO (2003). Concise International Chemical Assessment Document 55: Polychlorinated Biphenyls: Human Health Aspects. Geneva: World Health Organization.

Xie, W.-H., Shiu, W.-Y., and Mackay, D. (1997). A Review of the Effect of Salts on the Solubility of Organic Compounds in Seawater. Mar. Environ. Res. 44, 429-444. doi:10.1016/S0141-1136(97)00017-2

Zangrandi, M., Catsiki, V., and Avdis, O. L. V. (2005). The Sensitivity of MusselWatch Programmes to Detect Temporal Trends in the Bio-Availability of Metals. A Case Study of the Saronicos Gulf of Greece.

Zhan, Z., Wang, J., Peng, J., Xie, Q., Huang, Y., and Gao, Y. (2016). Sorption of $3,3^{\prime}, 4,4^{\prime}$-tetrachlorobiphenyl by Microplastics: A Case Study of Polypropylene. Mar. Pollut. Bull. 110, 559-563. doi:10.1016/ j.marpolbul.2016.05.036

Conflict of Interest: The author declares that the research was conducted in the absence of any commercial or financial relationships that could be construed as a potential conflict of interest.

Publisher's Note: All claims expressed in this article are solely those of the authors and do not necessarily represent those of their affiliated organizations, or those of the publisher, the editors and the reviewers. Any product that may be evaluated in this article, or claim that may be made by its manufacturer, is not guaranteed or endorsed by the publisher.

Copyright (c) 2022 Nunes. This is an open-access article distributed under the terms of the Creative Commons Attribution License (CC BY). The use, distribution or reproduction in other forums is permitted, provided the original author(s) and the copyright owner(s) are credited and that the original publication in this journal is cited, in accordance with accepted academic practice. No use, distribution or reproduction is permitted which does not comply with these terms. 